\title{
MODELLING AGRO-FORESTRY SYSTEMS FOR IMPROVED ECONOMIC PERFORMANCE: A COMPARATIVE ECONOMIC ANALYSIS
}

\author{
D M A H Senaratne ${ }^{1}$ and N K Senaratne ${ }^{2}$ \\ 'Land Use Policy Planning Division \\ ${ }^{2}$ Care international
}

Despite promising ecological features of various agro-forestry systems, adoption of these systems by farmers is not always encouraging. This is not surprising. as farmers are operating in a highly competitive commercial environment, where priority is given to economic goals rather than environmental goals. One solution is to develop AF models with species combinations that generate economic returns comparable to competing enterprises, simultaneously with environmental benefits.

The main objective of the current study is to investigate species combinations with improved economic performance. Here two AF practices in Sri Lanka, namely, coconut inter cropping and avenue cropping based on Gliricidia were considered. Information gathered both from primary and secondary sources were used in the study. A number of potential crops were categorized according to their income generating and resource utilisation patterns. Among them, there are perennials, semi perennials as well as seasonal crops. Two AF models were developed using Linear Programming technique. Models proposed jak, banana, pepper and coffee as the inter cropping combination which gives the highest economic performance under coconut based systems. In case of avenue cropping with Gliricidia, number of legumes and cereals along with banana was selected as the optimum combination. The economic performance of the developed models were assessed by cost-benefit analysis and their implications on a selected set of economic parameters have been discussed.

The whole exercise shows that, species combination of a system is an important aspect which determines the economic performance of the system. It further suggests that species combination can be manipulated to generate models with desired economic characteristics. Therefore, challenge ahead is to design models with species combinations that find a balance between economic and environmental objectives. 